\title{
QUALITY ASSESSMENT OF SELECTED ACCOUNTING INFORMATION SYSTEMS IN SLOVAKIA
}

\begin{abstract}
Linas STABINGIS, Faculty of Economics and Management, Aleksandras Stulginskis University, Universiteto st. 10, 53361 Akademija, Kaunas r., Lithuania; linas.stabingis@asu.lt (corresponding author) Anna LÁTEČKOVÁ, Faculty of Economics and Management at Slovak Agricultural University in Nitra, Tr. A. Hlinku 2, 94976 Nitra, Slovak Republic; anna.lateckova@uniag.sk

The quality assessment of accounting information systems (AIS) is complicated and important for scientific investigation. From theoretical point of view the difficulties lies in big amount of methods, proposed for AIS quality assessment. From practical points of view most of proposed methods are not suitable in particular situation and it is difficult to eliminate the subjectivity of respondents, participating in the survey.

In the stage of monographic research it was made analysis of scientific publications, dealing with understanding of AIS quality in face with technological progress of information and communication technologies (ICT) and changing of requirements, declared by endusers. In the stage of empirical investigation it was provided questioning of specialists, participating in accounting data processing using three different kinds of applied software and working in small and medium size agri-food enterprises in Slovak Republic. For processing of received data it was used method of multi-criteria evaluation. Following results of investigation and recommendations provided in standard ISO/IEC 25041:2012 and previous scientific publications it was made assessment of quality of investigated systems, identified strengths and weaknesses of these systems and reliability of investigation.
\end{abstract}

Keywords: Accounting information systems, quality assessment, multi-criteria evaluation.

\section{INTRODUCTION}

The management of enterprises and processing of accounting data in most cases is supported by use of information and communication technologies (ICT). Various kinds of software are widely used for data processing of transactions, business planing and support for business decisions. Most of big and some part of medium sized enterprises are using management information systems (MIS) with integrated processing of accounting data. Most small enterprises in Slovakia, including agri-food enterpises for processing of the accounting data are using specialised applied software or MS Excel.

Use of computers in the Slovak Republic have been started since the 1960s. The quality of automatic data processing at the given period depended at the technical level of computers - capacity, processing speed and etc. Significant changes taken place in the 1990s not only from the technical or social establishment points of view, but also were influenced by the emergence of the information society and the globalization of the world economy. A decline in prices of computer technology it was followed in this period. As a result of these process, increased demand for software for processing of accounting data. The offer of a large number of such kind of software has appeared and in the Slovak Republic. Over the next period only those providers of accounting information systems (AIS) remained on the market, who were able to propose the qualified and effective service for the customer. In the current period a relatively steady number of AIS providers are working in the Slovak Repoblic and these companies can be purposefully divided into three groups:

- companies with a small number of employees (up to 5 employees) are creating simple programs,

- companies with more employees (up to 30 employees) are creating user-friendly programs,

- large companies are creating complex enterprise integrated systems.

The owners and top managers of enterprises are interested not only in receiving the financial reports after the end of the month, the quarter or the year. In order to be competitive the company has to have the information system with the high quality solutions which not only ensure the recording and processing of data in real time, but also serves as a supporting tool the company's objectives should be achieved (Stuchlý, 2015). Now days all levels managers are interested in operative reports, data of which could be used for decision making. Due to this it is necessary the information system should support the planning and forecasting of production taking into consideration the specifics of activity of customers (Látečková, Bigasová, Stabingis, 2016). The specialists, dealing with accounting information in enterprises, sometimes critically valuate the functional abilities of software, used for the processing of accounting data, asking questions about

Copyright (C) 2017 The Authors. Published by Aleksandras Stulginskis University. This is an open-access article distributed under the terms of the Creative Commons Attribution License (CC-BY 4.0), which permits unrestricted use, distribution, and reproduction in any medium, provided the original author and source are credited. 
the sufficiency or insufficiency of the functional abilities and quality of such software and are ready to improve it or to change one kind of software into another (Stabingis, Látečková, 2016).

The process of quality assessment of accounting information systems (AIS) is complicated from both - theoretical and practical points of view. Due to this AIS quality assessment is an object of this scientific research. There are many methods could be used for AIS quality assessment, bus most of them are characterized as having limited reliability and depending on the aim of an investigation and/or environmental features, such as the size of the enterprise or the kind of its activity and the end-users' needs on the acceptability of reports for management, for example, abilities to generate the necessary content or grouping of the data in these reports (Stabingis, Látečková, 2016). Seeking successful investigation it is necessary to solve several complicated problems: a) to prepare the system of criterion and indicators; b) to prepare the metrics of indicators; c) to motivate the respondents to participate in the survey; and d) to explain the respondents the tasks for investigation and the essence of the description of AIS quality aspects they have to evaluate.

The scientific problem of research, presented in this paper, is to assess the quality of accounting information systems from the point of view of end-users in small and medium sized agri-food enterprises in Slovak Republic.

Object of research - the quality of AIS, used by small and medium sized agri-food enterprises in Slovak Republic.

The aim of the research - to provide the assessment of the quality of selected AIS, used by small and medium sized agri-food enterprises in Slovak Republic and to identify the strengths and weaknesses of analysed systems.

Main tasks of research:

1. To make an analysis of the methods, used for AIS quality assessment, and to choose one most suitable for use in small and medium sized agri-food enterprises.

2. To analyse the aspects, affecting quality of AIS and to prepare a system of criterion and indicators for assessment of quality of AIS used in small and medium sized agri-food enterprises in Slovak Republic.

3. To provide the questioning of specialists of accounting, working in small and medium sized agri-food enterprises in Slovak Republic, to identify their opinion on quality of these systems according the foreseen indicators and to calculate the common quality indexes of investigated AIS.

4. To identify the strengths and weaknesses of analysed AIS.

Research methods - monographic investigation, logical analysis and synthesis, comparison, multi-criterion analysis, summarising.

The main value of the provided research is the results of assessment of quality of AIS used in small and medium sized agri-food enterprises in Slovak Republic and identified strengths and weaknesses of investigated systems.

\section{DATA AND METHODS}

\section{Monographic analysis of the problem area}

The authors' of this paper agrees with considerations of other authors the quality assessment of accounting information systems (AIS) is a complex task. In order to analyse the quality of AIS, it is actual analysis of the concept "quality" in general and in context of constructional and functional nature of these systems.

According to Özkan (2006), quality is suitability of goods and (or) services to the users' expectations or users' needs. The processing of accounting data can be considered as a service provided to accountants, seeking to increase the productivity of data processing and guaranty the quality of final reports. As pointed Huang, J.H. and Chang, C.C. (2008), the quality of the service could be assessed at the time when the service is used. Lee (2011) indicates that the quality of service is closely related to the proper execution of work and customers' satisfaction. According to Hoyle (ISO 9000 Quality Systems Handbook..., 2015), combining a variety of quality concepts and definitions with the international quality standard ISO 9000:2000, quality can be expressed as a degree of services suitability to clearly specified or only implicit, compulsory or only desirable user's needs and expectations. Following ISO/IEC 20000-1:2011. Information technology... (2011), the quality can be evaluated according to three key aspects: quality of design, quality of product (service) and quality of usage. These definitions suggests that in process of investigation and evaluation of the quality of goods and (or) service, attention must be paid to the determination of consumer expectations and satisfaction (Lukoševičiūtè, Stabingis, 2012).

Many scientists believe that by assessing of the quality of AIS it is important to take into consideration the specific nature of these systems: design, installation and operation features as well as ability of consumers to use information and communication technologies. Özkan (2006) refers to three aspects which affect the quality of information systems: a) type of such systems, b) stakeholders of the systems and c) duration of these systems development. Michailescu, Carlsson, and Michailescu (2007) argues that the greatest effect on the quality of information systems has quality of management of such systems development, business processes, strategy and organizational issues.

Liang and Cheng (2009) in the process of assessment of the quality of information systems propose to consider the three most important aspects: a) the quality of information, b) the quality of the systems and c) the quality of service accessible using these systems. Huang and Chang (2008) stress that key influence on consumer satisfaction had the overall reliability of the information systems. These authors also point out importance for consumers to have the opportunity for easy, convenient and quick contact with the consultant, who could help in managing the information system not only in malfunctioning cases, but also during the provision of routine operation.

Reiter et al. (2014) believes the results of software quality estimation are affected by following three factors: the system, the context in which the system is used, and the software users. The system factors point out to the technical characteristics of a software product or services. The functionality of a software product, delay in data transmission, and a content of a media are examples of the system factors. Most of the system factors are relevant to the technical quality 
of the product or service (Fotrousi, Fricker, Fiedler, 2017). System factors, according Fotrousi et al. (2017), include the properties and characteristics of a system that reflect its technical quality, such as its performance, usability, and reliability (ISO/IEC 25010).

The context reflects the user environment, which is characterized by physical, social, economical and technical context factors (Reiter et al. 2014). The technical context factors are the system factors that are contextually related to the software product or service. According Mitra et al. (2011) as an example of the technical context factors could be mentionned the characteristics of the feedback tool and a device that the software product has interconnection with, such as the design layout, screen size and other.

The software users could be characterized by rather stable demographic, physical, and mental attributes, as well as more volatile attributes, such as temporary emotional attitudes (Fotrousi, Fricker, Fiedler, 2017). According Kujala and Miron-Shatz (2013) the human factors could be exemplified by mentioning needs, motivations, expectations, and moods of end-users. The users' perception of the product's quality is influenced by a variety of emotions (Fernández-Dols and Russell 2003), therefore, emotions are important factors to be considered while studying quality of various product, including software.

When interpreting user feedback, all three factors must be taken into consideration, since all of these factors, and not only the software system, affect human emotions (Barrett et al. 2011).

Analysis of mentioned above and others scientific publications allowed authors of this paper to identify the main aspects influencing the quality of AIS in small and medium sized enterprises (Stabingis, Látečková, 2016):

- Technology (hardware and software, used for data processing and transference);

- Institution (size and kind of activity of the enterprise);

- Environmental (information and communication);

- Organisation (responsibility of particular employees and information needs of decision makers).

\section{Methods used for assessment}

Many different information systems quality assessment models were developed in the last decades (Wagner, 2013). According to Al-Qutaish (2010), it is a real challenge to select which model to use. The method of multi criterion analysis it was created for identification of real property value, but Raupeliene (2003) sucessuly used it for evaluation of an effectiveness of AIS. Later on this method was adopted for quality assessment of information systems (Raupeliene \& Stabingis, 2006). Summarising ideas, presented in various scientific publication, and practical experience of the authors of this paper, the method of multi-criteria evaluation could be described as having the following advantages in case of use for the AIS quality assessment (Stabingis, Látečková, 2016):

1) Indicators could be expressed by quantitative and qualitative measures;

2) Different coefficients of importance of particular indicators could be used;

3) It is available elimination of some less important indicators already during the process of evaluation without changing the system of criteria and indicators;

4) It is possible identification of the strengths and weaknesses of assessed systems.

On the base of monographic research and following the recommendations of ISO/IEC 25041 (2012) and ISO/IEC 9126 (1991) the authors of this paper used the following criteria for AIS quality assessment: a) Functionality; b) Adequacy; c) Reliability; d) Complexity; e) Safety; f) Compatibility; g) Adaptability and h) Usability or convenience for users.

Stabingis (2010) made adoption of the recommendations of ISO/IEC 25041 for the evaluation of the AIS quality and prepared description of the mentioned above criterion taking into consideration the specifics of functioning and use of AIS. According this author (Stabingis, 2010):

1) The criterion of Functionality has to reflect the main abilities of software to provide necessary operations to process the accounting data, the sufficiency or insufficiency of these operational functions for successful use in practice in the particular enterprise.

2) The criterion of Adequacy has to reflect the abilities of software to provide the processing of accounting data following legal legislation and requirements of national or international standards of business accounting, corporate accounting policies and the users' needs.

3) The criterion of Reliability has to show the disruptions of accounting data processing due to various reasons and the frequency of these disruptions.

4) The criterion of Complexity has to reflect the degree of integrity of the processing of accounting data, including integrity of different sub-systems.

5) The criterion of Safety has to show the sufficiency or insufficiency of a different administrative, organisational, technical and software tools and measures and abilities to use them to ensure the safety of the system and accounting data, protection against all external and internal threats.

6) The criterion of Compatibility has to show the safe and stable compatibility of specialised software, used for the processing of accounting data, with technical and software platforms used in other companies and institutions.

7) The criterion of Adaptivity has to reflect the abilities of functioning of specialised software, used for the processing of accounting data, after some no essential changes in technical and program equipment or changes in requirements for the processing of accounting data.

8) The criterion of Usability (convenience for users) has to reflect the convenience of specialised software, used for the processing of accounting data, for end-users' in process of input of transactions' data, in receiving messages about mistakes, sufficiency and understandability of these messages, convenience of search of relevant data. 
For measuring of each criterion there were chosen several indicators, some examples of which are presented. For the evaluation of the criterion Functionality there were chosen 11 indicators, including: a) sufficiency of stabile and semistabile data files and rationality of its structure, b) sufficiency of tools for data import from other IS, c) sufficiency of tools for logical and mathematical checking of imputed (uploaded) data and d) sufficiency of tools for operative queries formation. For the evaluation of the criterion Adequacy there were chosen 7 indicators, including: a) Adequacy of data processing algorithms to legislative requirements, b) Sufficiency of indicators about each transaction could be stored in the database, c) Adequacy of reports to users' needs according their content. For the evaluation of the criterion Usability, there were chosen 10 indicators, including: a) convenience to use the primary data input forms, b) intelligibility (understability) of titles of indicators, which have be inputted, c) convenience to use the tools for collected data search. For the evaluation of other criterion there were chosen following number of indicators: a) Reliability -4 indicators, b) Complexity -6 indicators, c) Safety -7 indicators, d) Compatibility -4 indicators and e) Adaptability -4 indicators.

Experience of authors of this paper showed that respondents, involved in the process of AIS quality assessment, have difficulties in chosen of the score, which best of all reflect the quality of particular indicator. To avoid this problem and increase the objectiveness of research, the authors of this paper prepared metrics for evaluation of each indicator.

The assessment of the quality of AIS, used by small enterprises in Slovakia, it was made using method of the multi-criteria analysis by providing the following steps (Stabingis, Látečková, 2016):

1. Determinated the importance of the particular indicator on the meaning of each criterion.

2. Determinated the importance of the particular criterion on the mean of the common quality index.

3. Provided questioning of end-users and received meanings of evaluation of each AIS quality indicator.

4. Calculated an aggregated meaning of each indicator.

5. Calculated an aggregated meanings of each criteria.

6. Calculated the common quality index of each analysed AIS.

The relative weight method, suggested by the Zhang and Pham (2000), it was used for ranking of the indicators importance. Each expert $k$ can differently evaluate the importance of each indicator $i$. Expert or experts' group using this method has to apply the comparative method in points, for example, from 1 to 5 or to 10 to establish the importance of each indicator $r_{i k}$. Seeking to decrease the tendency of experts' opinion, averages of all estimations $z_{i}$ are calculated (Zhang and Pham, 2000).

\section{RESULTS AND DISCUSSION}

For investigation there were chosed only three AIS: Pohoda, Sidus and Helios, but agro-food enterprises in Slovak Republic are using and other programs for accounting data processing such as WINTES, AURUS, CODEX, SOFTIP, NORIS. It can be stated, that users are generally satisfied with analysed programs. From the point of view the accounting process, they can be classified as reliable. Software companies, that are operating these AIS, provide technical and expert advice at the required level as well as high-quality updates and upgrades for each version of software, so, these AIS are functioning in line with current legislation.

The collection of the data used in this paper it was made within the project VEGA "Increasing the efficiency of decision making by managers, with the support of information systems and accounting" (project registration number 1/0489/15) in a period of time from September 2015 till May 2017. Most part of respondents there were half past time students of Slovak Agricultural university in Nitra, who are working in small and medium sized agri-food enterprises. The respondents prior to present their opinion on the quality of the investigated AIS, were instructed on task of investigation and already had an understanding of essence of research and used methods. Total number of fulfilled questionnaires it was 46, but for AIS quality assessment there were used only 34 of them: 13 respondents evaluated the quality of AIS Pohoda, 15 respondents - AIS Sidus and 6 - AIS Helios.

All respondents, participated in the survey, expressed their opinion according presented metrics about quality score of all indicators included into survey. Extra questioning of respondents on importance of all indicators on the mean of particular criterion and importance of all criteria on the mean of the common index of quality of estimated AIS there were not provided. For calculation of aggregated means of indicators and criterion there were used presented in table 1 results of research, provided by Stabingis and Lateckova (2016).

Table 1. Aggregated means of the criterion of estimated AIS used in small agri-food enterprises in Lithuania and common quality indexes of these systems (Source: Stabingis and Lateckova, 2016)

\begin{tabular}{|l|l|c|c|c|c|}
\hline \multicolumn{1}{|c|}{ Criterion } & \multicolumn{2}{c|}{ Scores, provided by experts [0,10] } & \multirow{2}{*}{ Coefficient [0,1] } \\
\hline K1 & \multicolumn{1}{|c|}{ Title } & Min. & Max. & Average & \\
\hline K2 & Functionality & 9 & 10 & 9,7 & 0,1488 \\
\hline K3 & Adequacy & 8 & 9 & 8,4 & 0,1288 \\
\hline K4 & Reliability & 6 & 10 & 7,8 & 0,1196 \\
\hline K5 & Complexity & 7 & 8 & 7,7 & 0,1181 \\
\hline K6 & Safety & 7 & 9 & 8,1 & 0,1242 \\
\hline K7 & Compatibility & 6 & 9 & 7,6 & 0,1166 \\
\hline K8 & Adaptability & 6 & 8 & 6,9 & 0,1058 \\
\hline
\end{tabular}


According results presented in table 1 the most important is the criterion of Functionality (coefficient of importance of which is 0.1488 ), as slightly less important it was estimated criterion of Usability (coefficient of importance of which is 0.1381) and the smallest score of importance it was delivered to the criterion of Adaptability (mean of coefficient - 0.1058).

The results of the quality assessment of three AIS used in small medium sized agri-food enterprises in Slovak Republic are presented in the table 2.

The data presented in table 2 show that quality of AIS Helios was best assessed (common quality index is 0.83014 ). Common quality indexes of AIS Sidus and AIS Pohoda are consequently 0.72643 and 0.65087. Following recommendation the final result of estimation to express in word form the quality of AIS Helios could be estimated as "good" and the quality of AIS Sidus as well as AIS Pohoda as "satisfactory".

Table 2. Aggregated meanings of the criterion of estimated AIS used in small and medium sized agri-food enterprises in Slovakia and common quality indexes of these systems (source: prepared by the authors of this paper)

\begin{tabular}{|c|l|c|c|c|}
\hline \multicolumn{1}{|c|}{ Criterion } & \multicolumn{3}{c|}{ Aggregated meanings [0,1] } \\
\hline Code & \multicolumn{1}{|c|}{ Title } & AIS Pohoda & AIS Sidus & AIS Helios \\
\hline K1 & Functionality & 0.09546 & 0.11456 & 0.13417 \\
\hline K2 & Adequacy & 0.09564 & 0.09564 & 0.10303 \\
\hline K3 & Reliability & 0.09006 & 0.09618 & 0.10743 \\
\hline K4 & Complexity & 0.07045 & 0.07863 & 0.09324 \\
\hline K5 & Safety & 0.07073 & 0.06839 & 0.08238 \\
\hline K6 & Compatibility & 0.08133 & 0.10443 & 0.11015 \\
\hline K7 & Adaptability & 0.07500 & 0.07999 & 0.08991 \\
\hline K8 & Usability & 0.07220 & 0.08861 & 0.10983 \\
\hline Common quality index & 0.65087 & 0.72643 & 0.83014 \\
\hline
\end{tabular}

As it was mentioned before, the method of multi-criterion analysis allow not only assessment of the quality, but also identification of the strengths and weaknesses of analysed systems. The principles of strengths and weaknesses identification is shown by analysing the data, presented in table 3, on assessment of indicators, included into evaluation of the Usability criterion.

Table 3. Aggregated meanings of indicators, used for assessment of Usability criterion by estimating quality of AIS used in small and medium sized agri-food enterprises in Slovakia (source: prepared by the authors of this paper)

\begin{tabular}{|c|c|c|c|c|c|}
\hline \multicolumn{2}{|r|}{ Index } & \multirow{2}{*}{$\begin{array}{l}\text { Coefficient of } \\
\text { importance }\end{array}$} & \multicolumn{3}{|c|}{ Aggregated meanings $[0,1]$} \\
\hline Code & Title & & AIS Pohoda & AIS Sidus & AIS Helios \\
\hline I01 & Convenience to use the primary data input forms & 0.1163 & 0.09304 & 0.06978 & 0.06978 \\
\hline $\mathrm{I} 02$ & $\begin{array}{l}\text { Intelligibility (understandability) of titles or requisits, which have } \\
\text { be inputted }\end{array}$ & 0.1020 & 0.10200 & 0.08160 & 0.06120 \\
\hline I03 & Sufficiency of messages about mistakes & 0.1059 & 0.06354 & 0.10590 & 0.10590 \\
\hline I04 & Intelligibility of descriptions of mistakes & 0.0941 & 0.05646 & 0.03764 & 0.07528 \\
\hline $\mathrm{I} 05$ & Convenience to use the tools for collected data search & 0.1020 & 0.06120 & 0.06120 & 0.10200 \\
\hline I06 & Sufficiency of tools for mistakes search & 0.0941 & 0.01882 & 0.03764 & 0.03764 \\
\hline I07 & Convenience to use the service programmes & 0.0850 & 0.06800 & 0.06800 & 0.08500 \\
\hline $\mathrm{I} 08$ & $\begin{array}{l}\text { Convenience to use the tools for data selection in process of } \\
\text { reports formation }\end{array}$ & 0.1137 & 0.02274 & 0.06822 & 0.09096 \\
\hline I09 & Convenience to use the tools for data import from other IS & 0.0928 & 0.01856 & 0.05568 & 0.09280 \\
\hline $\mathrm{I} 10$ & Convenience to use the tools for data export to other IS & 0.0941 & 0.01882 & 0.05646 & 0.07528 \\
\hline
\end{tabular}

As it is shown in table 1, the Usability is second most important criterion, coefficient of importance of which is 0,1381. According the data, presented in table 2, indicators, most importantly affecting meaning of this criterion, are as follow: a) Convenience to use the primary data input forms (coefficient of importance -0.1163 ); b) Convenience to use the tools for data selection in process of reports formation (coefficient of importance - 0.1137); c) Sufficiency of messages about mistakes (coefficient of importance - 0.1059); d) Intelligibility (understandability) of titles or requisits, which have be inputted (coefficient of importance - 0.1020); and Convenience to use the tools for collected data search (coefficient of importance - 0.1020). All experts, participated in assessment of AIS Pohoda, higest score allocated for the indicator I2 (Intelligibility (understabillity) of titles of requisites, which have be inputted). Taking into consideration this indicator has second higest importance on the meaning of particular criteria, understabillity of titles of requisites, which have be inputted, could be defined as strength of AIS Pohoda. Following this logics of consideration, the strength of AIS Sidus is sufficiency of messages about mistakes (indicator I3, aggregated meaning 0.10590). The strength of AIS Helio is 
sufficiency of messages about mistakes (indicator I3, aggregated meaning 0.10590) and convenience to use the tools for collected data seach (indicator I5, aggregated meaning 0.10200).

Due to high importance (0.1137) and low aggregated meaning of quality (0.02274), as the weakness of AIS Pohoda could be identified insufficient convenience to use the tools for data selection in process of formation of reports (indicator I8). The weaknesses of AIS Sidus are: a) insufficient intelligibility of description of mistakes and insufficiency of tools for mistakes search (indicator accordingly I4 and I6, importance of both indicators -0.0941 and aggregated meanings of quality of both indicators - 0.03764). The weaknesses of AIS Helios is insufficiency of tools for mistakes search (indicator I6, aggregated meanings of quality - 0.03764). Moreover, the insufficiency of tools for mistakes search (indicator I6, aggregated meanings of quality - 0.01882) could be identified as weakness of other investigated AIS - Pohoda.

Authors of this paper, following the logics of consideration presented previously, identificated more strength and weaknesses of investigated AIS. Analysing the results of assesments of indicators, included into evaluation of Functionality criterion, it was identified that most important (coefficient of importance - 0.1117) indicator is Sufficiency of stabile and semi-stabile data files and rationality of its structure. Respondents evaluated quality of all investigates AIS with the higest score according this indicator (aggregated meanings of quality - 0.11170). As the strength of AIS Sidus and AIS Helios also could be identified sufficiency of tools for tax reports formation (indicator I8, aggregated meanings of quality - 0.09330). The weakness of AIS Pohoda and AIS Sidus is insufficiency of tools for formation of accountability (indicator I7, coefficient of importance - 0.1055, aggregated meanings of quality accordingly 0.02110 and 0.04220 ). As a weakness of AIS Helios could be inentified insufficiency of service programs (indicator I11, coefficient of importance -0.0687 , aggregated meaning of quality -0.04122 ).

Among indicators, included into evaluation of Complexity criterion, second in range of importance it was identified (coefficient of importance - 0.1645) indicator I 2 - Sufficiency of complexity of applied software. The features of the quality under this indicator could be assessed as the strength of investigated AIS (aggregated meanings of quality -0.13160 for AIS Pohoda and AIS Sidus as well as 0.16450 for AIS Helios). As the weakness of all investigated AIS could be identified insufficiency of possibilities to use ones inputted data for formation of all reports (indicator I4, coefficient of importance - 0.1776, aggregated meanings of quality - 0.07104 for AIS Pohoda and AIS Sidus as well as 0.10656 for AIS Helios).

The strength of all investigated AIS according criterion of Safety could be identified the data protection using software (indicator I4, coefficient of importance -0.1620 , aggregated meanings of quality -0.12960 ). The weakness of all investigated AIS according the same Safety criterion could be identified the data protection using technical equipment (indicator I3, coefficient of importance -0.1450 , aggregated meanings of quality -0.05800 ).

Analysing indicators, included into evaluation of Compatibility criterion, as the strength of all investigated AIS could be identified the Compatibility of AIS with IS of commercial banks (indicator I3, coefficient of importance 0.2547 , aggregated meanings of quality -0.25470 ). The weakness according this criterion could be identified only for AIS Pohoda and is insufficiency of Compatibility of AIS with other IS inside the company (indicator I2, coefficient of importance -0.2453 , aggregated meanings of quality -0.09812).

The strength and weakness of investigated AIS are clear and analysing indicators, included into evaluation of Adaptability criterion. As the strength could be inentified adaptabitity of reports formation softrware (indicator I3, coefficient of importance -0.2459 , aggregated meanings of quality -0.24590 ) and as the weakness - insufficiency of possibilities for generation of new data forms and reports (indicator I4, coefficient of importance -0.2328 , aggregated meanings of quality - 0.09312 for AIS Pohoda and AIS Sidus as well as 0.13968 for AIS Helios).

\section{CONCLUSIONS}

On the base of the results of monographic research and empiric investigation into the quality of accounting information systems, used by small and medium-size agri-food enterprises in Slovak Repoblic, there were prepared the following conclusions:

1. Quality AIS is considered to be a significant factor for achieving prosperity and long-term competitiveness of individual enterprises. From the point of view the managing and providing information to managers, it is considerible that AIS should be:

- reliable in the full range of features provided;

- $\quad$ acceptable to the specifics of agro-food enterprises;

- able to provide data processing into short-response results in real-time;

- modifiable and open for improvement as well as allowing remote access to data.

2. Common indexes of quality of assessed accounting information systems are following: for AIS Pohoda -0.65087 , for AIS Sidus -0.72645 and for AIS Helios - 0.83014. According the template for interpretation of results of estimation, the quality of AIS Helios could be estimated as "good" and the quality of AIS Pohoda and AIS Sidus - as "satisfactory".

3. The strengths of AIS Pohoda - sufficiency of stabile and semi-stabile data files and rationality of its structure, intelligibility (understabillity) of titles of requisites, which have be inputted, sufficiency of complexity of applied software, sufficiency of tools for data protection using software and compatibility of AIS with IS of commercial banks. The weakness of AIS Pohoda - insufficiency of tools for formation of accountability, insufficient convenience to use the tools for data selection in process of formation of reports, insufficiency of possibilities to use ones inputted data for formation of all reports, insufficiency of tools for mistakes search and data protection using technical equipment as well as insufficiency of compatibility of AIS with other IS inside the company. 
4. The strengths of AIS Sidus - sufficiency of tools for tax reports formation, sufficiency of messages about mistakes, sufficiency of complexity of applied software, sufficiency of tools for data protection using software and compatibility of AIS with IS of commercial banks and the weaknesses of this AIS - insufficiency of tools for formation of accountability, insufficient intelligibility of description of mistakes, insufficiency of tools for mistakes search, insufficiency of possibilities to use ones inputted data for formation of all reports insufficiency of tools for data protection using technical equipment.

5. The strengths of AIS Helios - sufficiency of tools for tax reports formation, sufficiency of messages about mistakes, sufficiency of complexity of applied software, sufficiency of tools for data protection using software and compatibility of AIS with IS of commercial banks and the weaknesses of this AIS - insufficiency of service programs, insufficiency of tools for mistakes search, insufficiency of possibilities to use ones inputted data for formation of all reports and insufficiency of tools for data protection using technical equipment.

6. The results of quality evaluation of AIS Pohoda and AIS Sidus could be considered as reliable, but the results of evaluation of AIS Helios due to low number of respondents are insufficiently reliable. Seeking to increase the reliability of AIS quality assessment have be increased the number of respondents and used structural interviews with the specialists directly involved not only in accaunting data processing, but and in preparation of accountability and other reports.

7. Use of innovations and efficiency are key concepts of the market and should be also reflected in the development of modern accounting information systems. In the current period, the cloud computing applications are a trend, whose the big advantage is remote access to data. Managers in agro-food industries are interested in these solutions because the data are available at any time and place, which is a great benefit for management and decision-making in Slovakia.

\section{REFERENCES}

1. Al-Qutaish, R. E. 2010. Quality models in software engineering literature: an analytical and comparative study. Journal of American Science, Vol. 6(3), pp. 166-175.

2. Barrett, L. F., Mesquita, B., Gendron, M. 2011. Context in emotion perception. Current Directions in Psychological Science, Vol. 20(5), pp. 286-290.

3. Fernández-Dols, J.-M., Russell, J. A. 2003. Emotions, affects, and mood in social judgements. Handbook of Psyhology. https://doi.org/10.1002/0471264385.wei0512/full

4. Fotrousi, F., Fricker, S.A., Fiedler, M. 2017. The effect of requests for user feedback on Quality of Experience. Software Quality Journal. 25, pp. 1 - 31. available at https://link.springer.com/article/10.1007/s11219-017-9373-7 (Accessed on 04/08/2017)

5. Huang, J.H., Chang, C.C. 2008. The Role of Personality Traits in Online Consumer Complaint Behaviour and Service Recovery Expectation. Social Behaviour and Personality An International Journal, Vol. 36(9), pp. 1223-1232. Available at https://www.sbpjournal.com/index.php/sbp/article/view/1793 (Accessed on 26/07/2017)

6. ISO/IEC 20000-1:2011. 2011. Information technology - Service management. Available at: http://www.iso.org/iso/catalogue_detail?csnumber=51986 (Accessed on 24/07/2017)

7. ISO/IEC 25041:2012. 2012. Systems and software engineering - Systems and software Quality Requirements and Evaluation (SQuaRE) - Evaluation guide for developers, acquirers and independent evaluators. Retrieved May 26, 2016, Available at https://www.iso.org/obp/ui/\#iso:std:iso-iec:25041:ed-1:v1:en (Accessed on 24/07/2017)

8. ISO 9000 Quality Systems Handbook-updated for the ISO 9001: 2015 standard: Increasing the Quality of an Organization's Outputs: 7th Edition. 2015. Available at https://www.routledge.com/ISO-9000-Quality-Systems-Handbook-updated-for-the-ISO9001-2015-standard/Hoyle/p/book/9781138188648 (Accessed on 24/07/2017)

1. ISO/IEC 9126 1991. Information technology - Software Product Evaluation - Quality characteristics and guidelines for their use. Available at https://books.google.lt/books/about/ISO_IEC_9126.html?id=_NvIZwEACAAJ\&redir_esc=y (Accessed on 24/07/2017)

2. Kujala, S., Miron-Shatz, T. 2013. Emotions, experiences and usability in real-life mobile phone use. Conference on Human Factors in Computing Systems CHI 2013, pp. 1061-1070, Paris, France. Available at https://ehealth-syte.com/wpcontent/uploads/2015/10/Emotions-experiences-and-usability-in-real-life-mobile-phone-use.pdf (Accessed on 18/07/2017)

3. Látečková, A., Bigasová, Z., Stabingis, L. 2016. Accounting information systems in business management. International Scientific Days 2016: The Agri-Food Value Chain: Challenges for Natural Resources Management and Society, Nitra, Slovak Republic. $\quad$ pp. 403-409. Available at http://spu.fem.uniag.sk/mvd2016/proceedings/en/articles/s6/lateckova bigasova stabingis.pdf (Accessed on 04/08/2017)

4. Liang, C. J., Chen, H. J. 2009. A study of the impact of website quality on customer relationship performance. Total Quality Management and Business Excellence, Vol. 20(9), pp. 971-988. https://doi.org/10.1080/14783360903181784

5. Lukoševičiūtè, D., Stabingis, L. 2012. Valstybinès mokesčiu inspekcijos internetu teikiamų paslaugų kokybès tyrimas $=$ Research of quality of online services provided by the state tax inspectorate. Proceedings book of international scientific conference Science and studies of accounting and finaces: problems and perspectives. / Akademija, kaunas r., Lithuania, pp. 130-141. [In Lithuanian]

9. Michailescu, D.; Carlsson, S.A.; Michailescu M. 2007. Evaluating Enterprise Systems Implementation Methodologies In Action: Focusing Formalised and Situational Aspects. Electronic Journal of Information Systems Evaluation, Vol. 10(1), pp. 83-90. http://www.ejise.com/volume10/issue1/p83 (Accessed on 13/07/2017)

10. Mitra, K., Zaslavsky, A., Åhlund, C. 2011. A probabilistic context-aware approach for quality of experience measurement in pervasive systems. Proceedings of the 26th ACM symposium on applied computing, Taichung, Taiwan, pp. 419-424. Available at http://dl.acm.org/citation.cfm?id=1982276 (accessed on 28/07/2017) 
11. Özkan, S. 2006. A Process Capability Approach to Information Systems Effectiveness Evaluation. Electronic Journal of Information Systems Evaluation, Vol. 9(1), pp. 7-14. Available at http://www.ejise.com/front/search/index.html (Accessed on 12/07/2017)

12. Raupelienè, A. 2003. Imonès apskaitos informacinès sistemos efektyvumo vertinimo modelis: daktaro disertacija $=$ Model for evaluation of effectiveness of the enterprise's counting information system: Doctoral dissertation, faculty of Economics and Management, Lithuanian University of Agriculture. [In Lithuanian]

13. Raupelienè, A., Stabingis, L. 2006. Crop declaration and control information system quality evaluation. Economics and Rural Development, Vol. 2(1), pp.38-45.

14. Reiter, U., Brunnström, K., De Moor, K., Larabi, M.-C., Pereira, M., Pinheiro, A., et al. 2014. Factors influencing quality of experience. Quality of experience, Springer, pp. 55-72. Available at https://link.springer.com/chapter/10.1007\%2F978-3-31902681-7_4 (accessed on 16/06/2017)

15. Stabingis, L.; Látečková, A. 2016. Quality assessment of accounting Information Systems Used by Small Enterprises in Lithuania. Proceedings ICABR 2016: XI International Conference on Applied Business Research, Bangkok, Thailand, pp. 446-455. Available at http://www.kimba.ku.ac.th/icabr2016/fullpapers/icabr2016.pdf (Accessed on 06/06/2017)

16. Stabingis, L. 2010. Žemès ūkio veiklą vykdančių subjektų apskaitos informacijos tvarkymas naudojantis kompiuteriais = Processing of accounting information using computers in agricultural enterprises. Available at http://dspace.lzuu.lt/handle/1/384 (accessed on 20/06/2017) [In Lithuanian]

17. Stuchly P., Krutakova P. 2015. Analysis of a Process in Relation to the Enterprise Information System. Proceedings ICABR 2015, Brno, Czeck Republic, pp. 946-950. Available at http://www.icabr.com/fullpapers/icabr2015.pdf (Accessed on 27/06/2017)

18. Wagner, S. 2013. Software product quality control. Berlin: Springer. Available at http://www.springer.com/la/book/9783642385704 (Accessed on 28/06/2017)

19. Zhang X., Pham H. 2000. An analysis of factors affecting software reliability. The Journal of Systems and Software, Vol. 50, pp. 43-56. https://doi.org/10.1016/S0164-1212(99)00075-8 